\title{
A simple numerical analyses software for predicting water table height in subsurface drainage
}

\author{
Paulo Jorge Castanheira • Francisco Lúcio Santos
}

Published online: 26 August 2009

(C) Springer Science + Business Media B.V. 2009

\begin{abstract}
A two dimensional saturated-unsaturated Galerkin finite element numerical model was used to predict water table height between parallel drains. A user-friendly software (DRENAFEM) was developed to allow for the calculation of the distance between drains and the water table height at middle space between drains. It also allows for determination of variations of the total head throughout the entire geometric space considered in the model. Such facts lead to the design of flow nets with streams lines and equipotentials. The numerical drain outflow is also obtained by using the radial flow equation, conservation of mass and finite element analysis. The results obtained with the model agree well with Khirkam's and Hooghoudt analytical solution for the distribution of total head in ideal drains and for the total head calculations midway between drains.
\end{abstract}

Keywords Subsuperficial drainage $\cdot$ Numerical simulation

\section{Introduction}

The movement of the water and solutes in the vadose zone has had an increasing interest in diverse areas of science as the hydrology, agricultural and soil engineering. The knowledge of the processes of transfer of water in the soil and ways to foresee, predict and control water movement in the soil are important in the simulation of the behaviour of water table and dispersion of solutes, in particular for the subsurface drainage., From the solution of transient saturated/unsaturated flow equation of Richards the oscillation of the water table levels and drain flow rate can be simulated between two parallel drains in response to a recharge due precipitation and/or irrigation, as well as its variation in time.

Numerous solutions for the considered problem are found in the literature. The majority of the proposed solutions are based on the hypotheses of Dupuit-Forchheimer which, when certain initial and boundary conditions are established, allow for an exact analytical solution of the

P. J. Castanheira $(\bowtie) \cdot$ F. L. Santos

Rural Engineering Department, University of Évora, Apartado 94, 7002-554 Evora Codex, Portugal e-mail: castanheira.p@gmail.com 
steady state saturated flow equation of Laplace (Yeh 1999). The mathematical solutions are usually of two dimensions (Kirkham 1966; Gureghian and Youngs 1975) and well suited for a variety of applications and well defined for particular cases, but they do not comply very well when more complex problems arise, for instance when the heterogeneity and anisotropy of the soil are to be taken into consideration, when the unsaturated flow is also to be considered, and when there exist complex and irregular boundary conditions for drain boundary. Only way to solve the problem is to use numerical methods.

The finite element method is a numerical method that is used as a numerical approach of the transient saturate/unsaturated flow, especially in the search of solutions for the water table level between two ditches or in a riverbank. France et al. (1971);Desai (1972); Gureghian and Youngs (1975) had applied the method to solve the problem in two dimensions for steady state and saturated flow, to determine the position of the water table surface, subject to different boundary conditions. Neuman (1973) solved the same type of problem considering the contribution of the flow in the unsaturated zone. The application of the same numerical approach solution to subsurface drainage by drain pipes is described in Zaradny and Feddes (1979). The method suffered further improvements to allow it to represent drains in the numerical mesh (Tarboton and Wallender 2000) and also suffered further numerical refinements to diminish the loss of mass and the numerical oscillation in the computation (Pan et al. 1996).

There are several finite element computer codes to numerically solve the water flow in soil, like the HYDRUS2D (Simunek et al. 1999), SWMS_3D (Simunek et al. 1995) Aquifem-N (Townley 1990), however they all need a relatively complex set of initial and boundary conditions.

The objective of this work is to propose a friendly computer software which solves the transient vertical unsaturated flow in a sub-superficial drainage situation, drained by parallel pipe drains set at the same depth Numerical approach is compared with the analytical solution for a well-defined situation. In the case, from the well known Hooghoudt equation and Kirkham potential theory calculations. The results of our proposed model are also compared with the results generated byHydrus2D model of Simunek et al. (1999).

The model allows also for the simulation of drain flow rate from the concept of the mass conservation. The solutions were also compared with the approximate solution in steady state simulation.

\section{Materials and methods}

The theory

With water flowing into an elementary prism of soil with unit dimensions, the flow leaving the soil is equal to that which enters it, deduced of the variation of volume of stored water. This fact translates the principle of the mass conservation that, applied jointly with the dynamic equation of Darcy, allows for the generalized flow equation into the soil.

Without great margin of error for the type of problem considered, that the water and the soil are incompressible and they do not change mass between themselves, that thermal gradients do not exist in the soil and the law of Darcy is valid in all the domain of the flow, the general flow equation-Richards equation-can be written as

$$
C(\psi) \frac{\partial \psi}{\partial \mathrm{t}}=\nabla(\mathrm{K}(\psi) \nabla(z+\psi))
$$


where $\mathrm{K}(\psi)$ is the unsaturated hydraulic conductivity (m.day $\left.{ }^{-1}\right), \mathrm{C}(\psi)$ the soil water capacity $\left(\mathrm{m}^{-1}\right)$, representing the slop of the moisture retention curve in the soil, $\psi$ the pressure water potential related to the weight of water $(\mathrm{m}), \mathrm{z}$ the gravitational potential $(\mathrm{m})$ and $\mathrm{t}$ the time (days).

Applying the Galerkin finite element approach to the generalized flow equation, transforming the resulting integrals into matrices and adding all the elements of the domain a global matrice is obtained, for where the formulation of the weighed residuals for steady state and transient flow is written as:

$$
[C(\psi)]\left\{\frac{\partial \psi}{\partial t}\right\}+[K(\psi)]\{\psi\}=\{F\}
$$

where

$$
\begin{aligned}
& {[C(\psi)]=\sum_{e} C_{i j}^{e}(\psi),} \\
& C_{i j}^{e}=\int_{\Omega} C(\psi) N_{i} N_{j} d \Omega \\
& {[K(\psi)]=\sum_{e} K_{i j}^{e}(\psi)} \\
& K_{i j}^{e}=\int_{\Omega}\left[K_{x}(\psi) \frac{\partial N_{i}}{\partial x} \frac{\partial N_{j}}{\partial x}+K_{z}(\psi) \frac{\partial N_{i}}{\partial z} \frac{\partial N_{j}}{\partial z}\right] d \Omega \\
& \{F\}=\sum_{e} F_{i}^{e} \\
& F_{i}^{e}=-\int_{\Omega} K_{z}(\psi) \frac{\partial N_{i}}{\partial z} d \Omega+\int_{\Gamma} N_{i} r_{n} d \Gamma
\end{aligned}
$$

$\mathrm{Ni}, \mathrm{Nj}$ are the element interpolation functions, $\Omega$ the flow domain and $\Gamma$ the boundary segment. The matrix $[\mathrm{C}(\psi)]$ is a diagonal matrix carrying the coefficients of specific capacity and the matrix $[\mathrm{K}(\psi)]$ is a symmetrical matrix, with a positive dominant diagonal line with coefficients of the hydraulic conductivity. The vector $\{\mathrm{F}\}$ is the summation of all flows that enter or leave the system with the flow gravitational component. Accordingly, the value of the flows is equal to zero when no water enter or exit the system, negative when it exits and positive when it enters the system. $r_{n}$ is the component of flux normal to the soil surface.

The numerical model

Placing the drains to the same depth between the horizontal soil surface and a deeper impermeable layer, the space between any two drains becomes symmetrical and the problem can be represented as in Fig. 1.

The boundary conditions for the solution of a problem of this king can be classified in two categories of the essential type, also known as the Dirichlet boundary condition and 2) the natural type or Neumann boundary condition. boundary AB is of the natural type, therefore to each node of the segment it is possible to apply one flux lower of the soil infiltration capacity. The remaining borders are taken as having zero flow, that is, without entrance or exit of water. the drain, it is represented by only one node in the point, with a border of the type essential, since the total potential will equal there the gravitational 


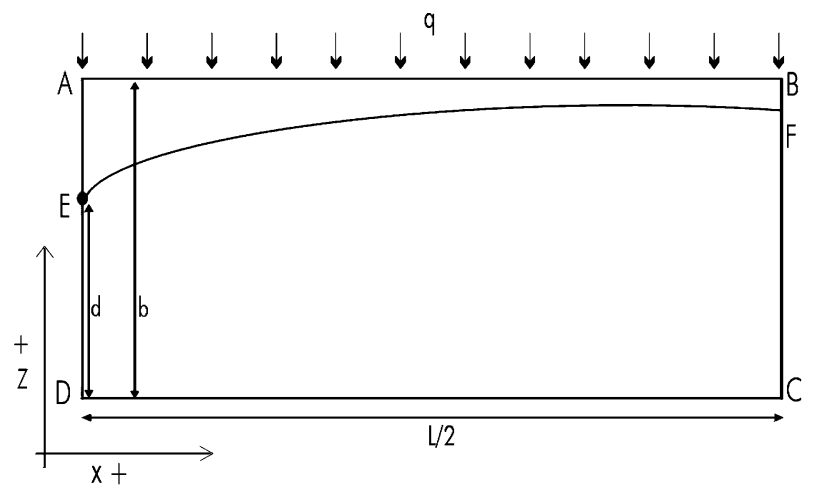

Fig. 1 The flow domain in steady state regime

potential, allowing for the potential of pressure in the drain to become zero (atmospheric pressure).

Mathematically terms the boundary and initial conditions are written as:

$$
\begin{aligned}
& \text { AED : } K_{x x}(\psi) \frac{\partial \psi}{\partial x}=0, x=0,0 \leq z \leq b, t \geq 0 \\
& \text { DC : } \quad K_{z z}(\psi) \frac{\partial \psi}{\partial z}+K_{z z}(\psi)=0, z=0,0 \leq x \leq \frac{L}{2}, t \geq 0 ; \\
& \text { BC : } \quad K_{x x}(\psi) \frac{\partial \psi}{\partial x}=0, x=\frac{L}{2}, 0 \leq z \leq b, t \geq 0 ; \\
& \text { AB : } \quad q=\left(K_{z z}(\psi) \frac{\partial \psi}{\partial z}+K_{z z}(\psi)\right), z=b, 0 \leq x \leq \frac{L}{2}, t \geq 0 \text { or } \psi=0, \mathrm{t}>0 ; \\
& \text { E : } \quad(\text { drain node }) \psi=0, \mathrm{t} \geq 0,
\end{aligned}
$$

A computer program (DRENAFEM) was designed to solve Eq. 1, subjected to boundary an initial conditions where the drain is represented as one node and the surrounding elements have the values of hydraulic conductivity adjusted from one factor, according to the Vimoke and Taylor (1962) approach, also described by in Fipps and Skaggs (1986). Anisotropy in the hydraulic conductivity anisotropy on vertical and horizontal directions, two soil layers and the Brooks and Corey and van Genucthen (1980) retention models were included into the model. The final software makes space discretization of 1,520 triangles and 820 nodes, with larger mesh density in the unsaturated zone and near the drain.

Figure 2 shows the program main window where the geometry problem is defined, as well as the soil physics parameters such as hydraulic conductivity, soil-water retention and the steady drainage flux. The model has the capability to simulate ideal and non-ideal drains, and by assigning backpressure to the drain controlled drainage problems can also be simulated.. In the absence of real values, the model suggest values for use with soil-water retention curves as well as saturated hydraulic conductivity values, all based in the soil 


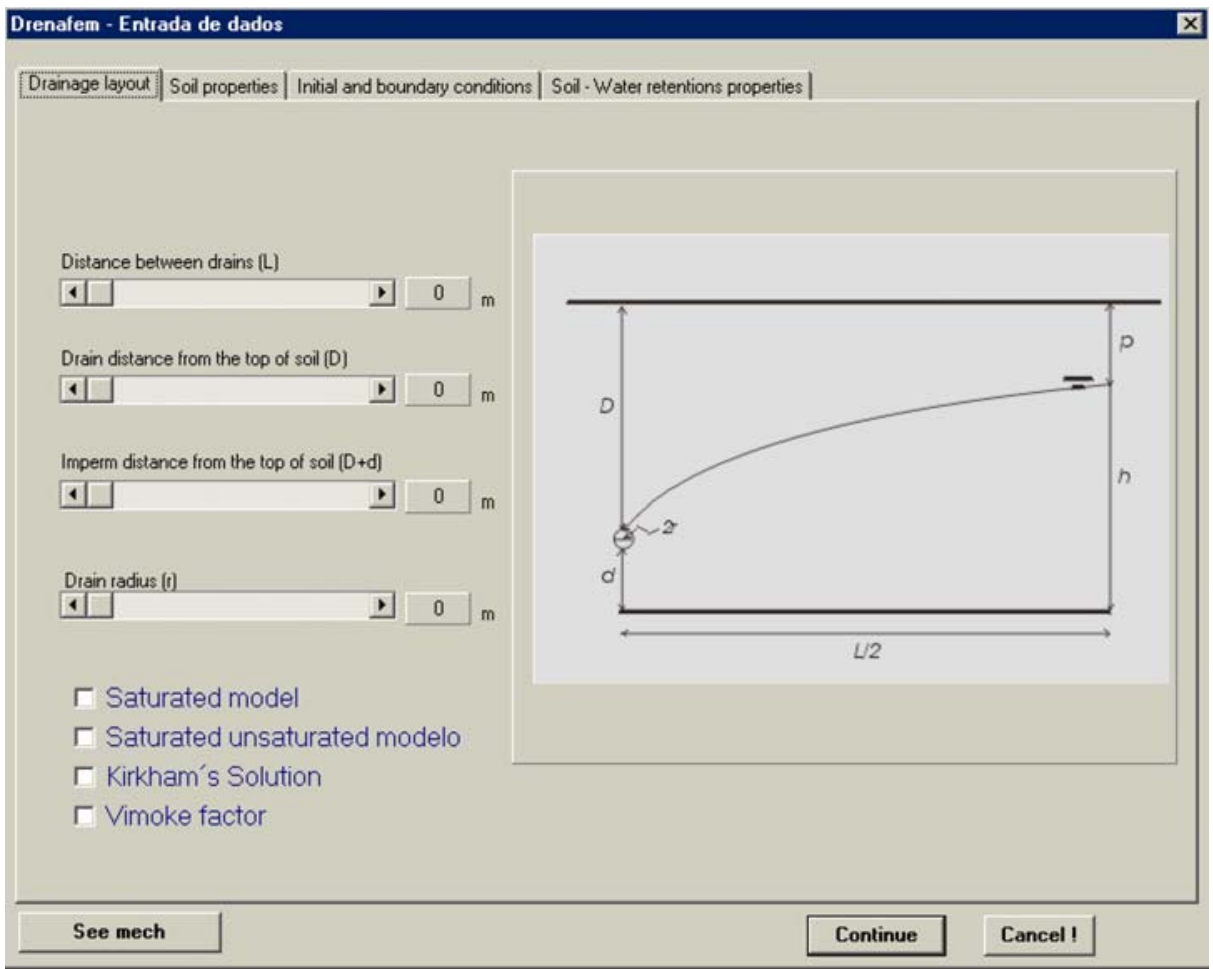

Fig. 2 The main window of software

texture considered for the problem. It also automatically builds up the finite element mesh and in the transient state mode it chooses the ideal time step to prevent numerical difficulties and run-time errors. The time spent to obtain a solution depends of the computer performance, with about 1 min time spent to find a steady state solution in a Pentium IV at $800 \mathrm{Mhz}$. In a transient state simulation mode the run time depends on the total time of the period simulation, with several minutes expected for the described above Pentium machine.

Figure 3 shows the results of a steady state run where the water table shape is presented as well as the head distribution from the drain to midpoint between drains, and the numerical drain flow.

Analytical solutions of the problem

For testing the reliability of a numerical model the usual procedure is to compare the obtained results with well know solutions. We chose two analytical solutions based on different theory, and one numerical solution offered by a commercial software. Kirkham et al. (1974), based in the theory of potentials considered the analytical determination of our same problem. In their approach they did not consider the effect of the unsaturated zone in the flow in solving the Laplace's equation, is consequently, different from the approach used in this work. Kirkham et al. assume that the head loss in the zone between the water table surface and the horizontal plan of the drains is small when compared to the head loss in the remaining region of the flow. They also consider that the soil $\mathrm{f}$ above the plan of 


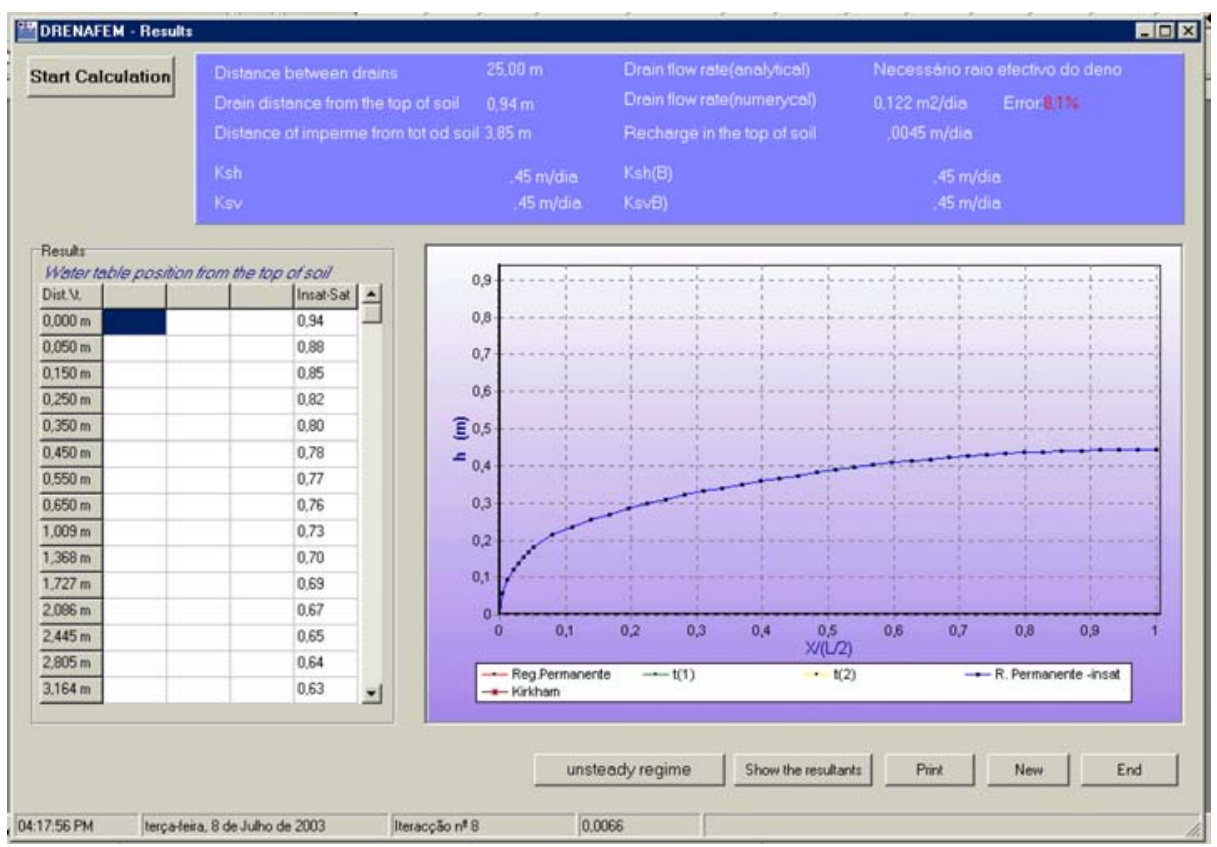

Fig. 3 The steady state window result

drains is replaced by fictitious membranes and gravel with infinite hydraulic conductivity, so that the standard equipotential lines in that zone of flow above the horizontal drains plan has no solution with their method.

The drains also are dealt with thickness zero and equal width to the radius. The model of Kirkham also assumes that the flow above of the horizontal plan of the drains is vertical in the unsaturated zone and that in the saturated zone it obeys the conventional way of looking at the flow, that is an horizontal flow.

The model results were compared with the widely used equation for drain spacing calculation based in the Boussinesq equation, known as the Hooghoudt equation

$$
q=\frac{4 K_{s} h_{m}^{2}+8 K_{s} d_{e} h_{m}}{L^{2}}
$$

where $d_{e}$ is the depth of the equivalent depth layer, used to correct the convergence of the radial flow near the drain, $\mathrm{h}_{\mathrm{m}}$ the water table above the drain at the midpoint between drains and Ks the saturated hydraulic conductivity, L the space between two drains and $\mathrm{q}$ the steady drainage flux, numerically the same at $r_{n}$ in the steady state regime.

\section{Results and discussions}

Several calculations were performed to test the numerical results obtained. One compared the elevation of the water table above the drain at the midpoint between drains with the Hooghoudt analytical solution.

Hooghoudt in his expression for the shape of the water table as an ellipse assumes that the constant value of the flow $q$ that crosses the water table surface is equally removed 
between the drains. In steady state this is true for the numerical approach. The steady drainage flux in the surface of soil has the same value as that the one that crosses the water table surface. Figure 4 shows the good agreement obtained between our numerical approach and the Hooghoudt equation, for several geometric conditions. The exception is when the water table is near or above?? the surface. In this case the midpoint head value obtained with the numerical simulation is larger above the drains possibly due of the effect of capillary fringe in the vadose zone. As observed, the Hooghoudt equation results are no longer valid for pounded water table. Figure 4 also shows the effect of drain radius on the obtained results, and the need for a numerical model that simulates well the behaviour of the drain hole as a single mesh node. For higher values of $\mathrm{q} / \mathrm{Ks}$ ratio, the drain radius effects have influence in the results, with the need to adjust the elements surrounding the drain node to best simulate drainage flow. For lower $\mathrm{q} / \mathrm{Ks}$ ratio that need is no longer so evident.

Figure 5 shows the potential patterns computed with the finite element method (doted lines) and the Khirkam solution (solid lines), and also the water table configuration from the drain to the midpoint of drains.

The difference in equipotentials between the two methods explains the observed differences for the different position of the water table. The drain radius influences greatly the distribution of the potentials and the position and shape of the water table. Drain radius must be reduced in the Kirkham approach to obtain satisfactory agreement of the equipotential lines for the two methods, as seen in Fig. 5a. The values of the drain radius used are respectively $0,05 \mathrm{~m}$ and $0,005 \mathrm{~m}$. In the first case, the level of the water table was lower than the level obtained with the numerical analysis simulation and, as a result the hydraulic potential is lower for all the flow points. The variations correspond to the difference observed between the positions of the two free surfaces. So, to obtain the same values of water table level it is necessary to attribute an abnormally small value to the drain radius, inducing a radial flow or an entrance resistance in the case of the Kirkham analysis. Figure 5b) In doing so, the agreement between the water table shape and equipotential lines is satisfactory in both methods, especially at the mid point between the drains. However, near the drain the potential distribution estimates higher values for the hydraulic potential. This aspect of the problem leads us to believe that a sole analysis of the head at the half distance of the drains is not able to inform in absolute
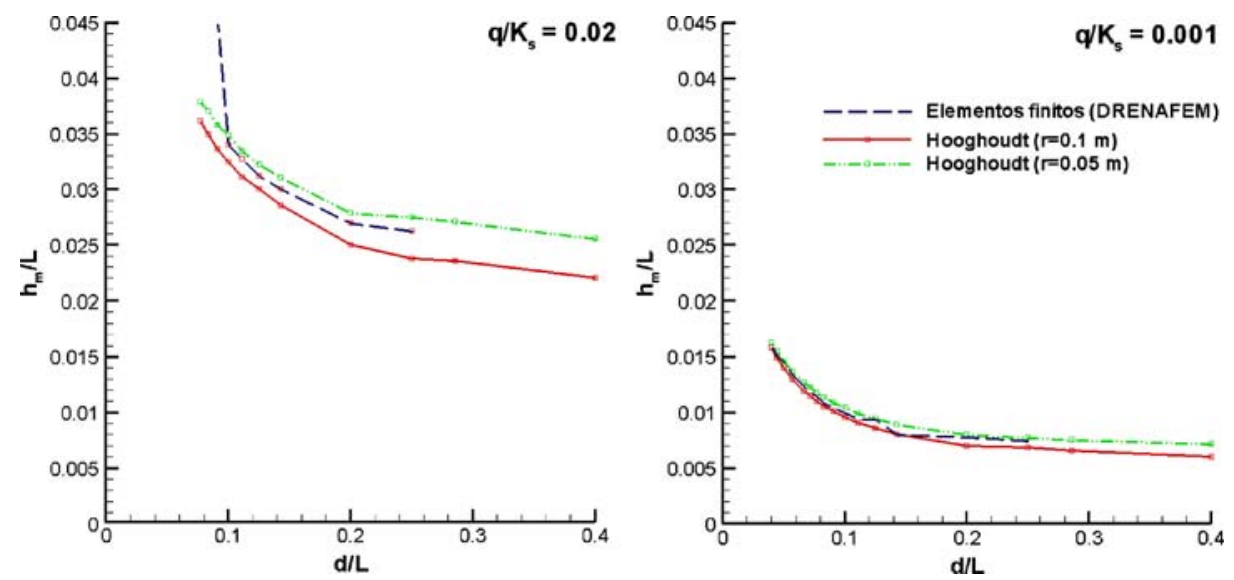

Fig. 4 Variations of the $h_{m} / L$ ratio with $d / L$ ratio for different $q / K_{s}$ ratio and real drain radius. Simulations are made for a clay soil in a homogeneous and isotropic medium 

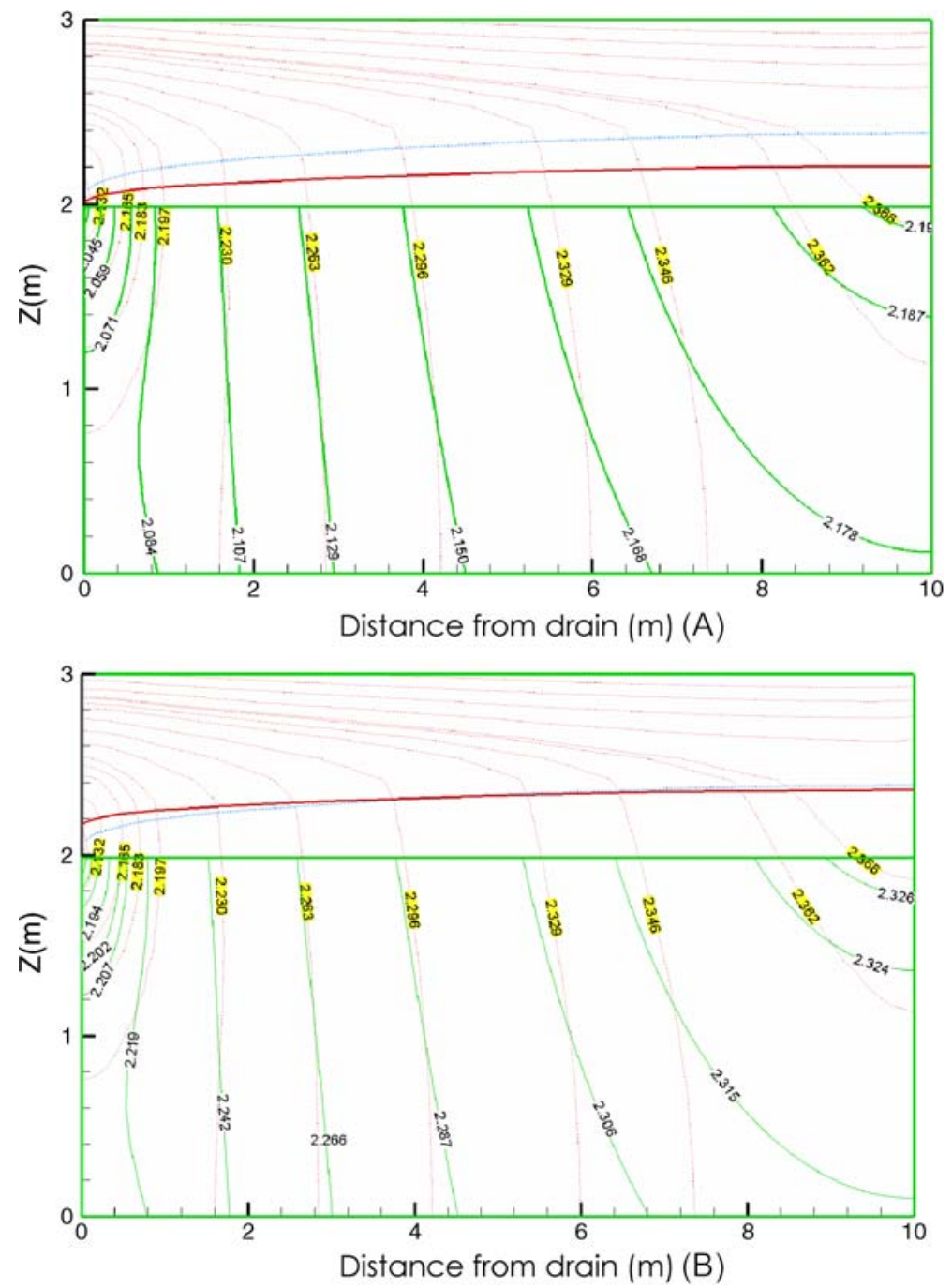

Fig. 5 Comparison of the equipotential lines and the position of the water table according to Kirkham (solid line) and of the numerical model (doted line).Simulation made for $\mathrm{L}=20 \mathrm{~m}, \mathrm{Ks}=1,5$ mday $^{-1}$, imperme barrier at the depth of $3 \mathrm{~m}$, drain at depth of $1 \mathrm{~m}$, VG parameters: $n=1.09, \theta_{\mathrm{s}}=0,36 \mathrm{~m} 3 \mathrm{~m}^{-3}, \theta_{\mathrm{r}}=0,07 \mathrm{~m} 3 \mathrm{~m}^{-3}$ e $\lambda=0,5 \mathrm{~m}^{-1}$, $\mathrm{q}=0.002$ mday $^{-1}$ and $r=0,05 \mathrm{~m}$ a and $r=0.005 \mathrm{~m} \mathrm{~b}$

of the adjustment between different methods of calculation. Some differences, however less evident that the above, also exist in the way drainage occurs. The analysis using Kirkham method practically considers a vertical flow in the corresponding zone more significantly at the half distance of the drains and also shows a trend of if becoming horizontal for distances close to the drains. The confluence of the flows for the drain (radial flow), also starts at lesser distances of the drain when compared to the numerical analysis solution. The smaller level of water table obtained with the Kirkham approach, beyond the value attributed to the drain radius can be explanation in the fact of the flow above of the plan of the drains being considered vertical and the Kirkham analysis considering not important loss of head in this region. 
However, the resultant equipotentials of the numerical analysis show that the flow is practically horizontal, being the simplification made by Kirkham partially responsibly the difference in the results. Also below of the plan level of the drains a zone there is a definite horizontal drain flow what does not happen when the solution of Kirkham.

To analyse the weight of the restrictions in the observed differences, as well as the precision of the numerical method, the HYDRUS2D (Simunek et al. 1999), which uses a finite element method was compared to our model. HYDRUS2D was used for simulations with a mesh of regular space and 4,640 triangles that correspond 3,042 nodes. The drain in the HYDRUS2D is also represented by only one node adjusted to the mesh by using the Vimoke adjustment.

Several calculations were performed in the unsteady state mode, for a period of 5 days, considering as the initial condition the soil a profile fully water saturated and a recharge $\mathrm{q}$ of 0 mday $^{-1}$. Despite the denser mesh of triangles of HYDRUS2D when compared to our model, the regular mesh did not allow to greater density next to the drain where larger values of hydraulic gradients were expected. The results are obtained directly in the model DRENAFEM, while for the HYDRUS2D model the solution is obtained by inspection of the hydraulic head in the node situated in the impermeable barrier, exactly half distance between the drains, deduced of the distance of the drain to the impermeable layer. The obtained results are shown in Fig. 6.

During the $24 \mathrm{~h}$ simulation period the values of $h_{m}$ diverge slightly, due to the large space discretization resources of the HYDRUS2D model, and more important, due to the use of lesser intervals of time as verified for the smaller distances of the points of the line. However, it is in the numerical method used in the two models to solve the system of equations that they are, in essence, different. While the DRENAFEM model uses the direct method of LU decomposition for solving the system of equations the HYDROS2D uses the indirect method of preconditioning conjugate gradient method, for faster and relatively little expected problems with the round off of errors. These aspects contribute for the differences observed in the obtained results. The execution time was the same. Taking into account differences in the dimension of the matrices set up fro the problem, the HYDRUS2D model is very fast.

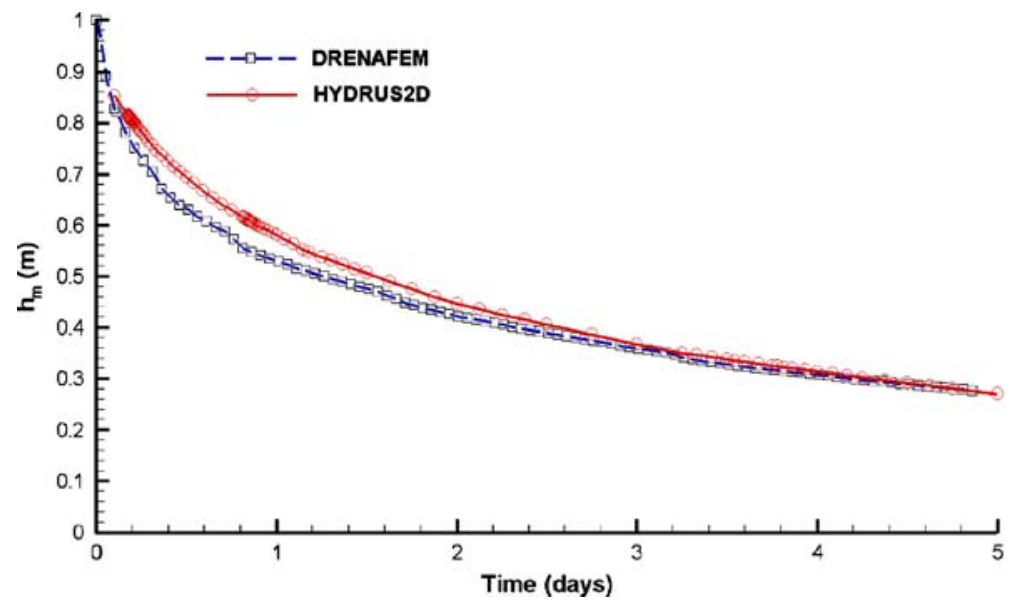

Fig. $6 \mathrm{hm}$ variation in five days period for two software packages 


\section{Conclusion}

The DRENAFEM numerical model presented good agreement in results when compared to the Hooghoudt analytical solution for a homogeneous and isotropic soil, assuring that the hydraulic head at the mid point between the drains can be obtained numerically with a friendly software. All what is required is a few soil and geometric parameters to obtain steady state solutions.

When compared to Kirkham method of evaluation the results show that the drain radius influences the shape of the water table and as result a different flow pattern is obtained with the DRENAFEM model, especially in what concerns the calculation of the head above the vertical plain of drain. So, despite the inherent differences of the two methods, the representation of a drain in a mesh as a one single node must suffer improvements to handle the simulated problem. Also differences were observed for the field potential distribution due to differences in the drain radius and in the initial assumptions made for both models.

Despite differences in the nature of the used numerical method to solve the system of equations and the required speed a reasonable agreement was obtained between the results of the DRENAFEM model and the results obtained with the Hydrus2D model simulating an unsteady flow regime.

Acknowledgements This work was supported by funds provided by project POCTI/32847/AGR/Fundação para Ciência e Tecnologia/Portugal.

\section{References}

Desai C (1972) Seepage analysis of earth banks under drawdown. J Soil Mech Found Div 98:1143-1161 Fipps G, Skaggs R (1986) Drain as a boundary condition in finite elements. Water Resour Res 22(11):1613-1621 France P, Parekh C, Peters J, Taylor C (1971) Numerical analysis of free surface seepage problems. J Irrig Drain Div 97:165-179

Gureghian A, Youngs E (1975) The calculation of steady state water table heights in drained soils by means of the finite-element method. J Hydrol (Amst) 27:15-32. doi:10.1016/0022-1694(75)90096-7

Kirkham D (1966) Steady state theories for drainage. J Irrig Drain Div 92:19-39

Kirkham D, Toksoz S, Ploeg R (1974) Steady flow to drains and wells. In Drainage for Agriculture, editado por Van Shilfgaarde, ASA, Agronomy series 17

Neuman S (1973) Saturated-unsaturated seepage by finite elements. J. Hydraul Div. A.S.C.E. 99(HY 12):2233-2250

Pan L, Warrick A, Wierenga J (1996) Finite element methods for modelling water flow in variably saturated porous media: numerical oscillation and mass-distributed schemes. Water Resour Res 32(6):1883-1889. doi:10.1029/96WR00753

Simunek J, Huang K, van Genucthen MT (1995) The SWMS_3D code for simulating water flow and solute transport in three dimensional variably saturated media. Research report n 139, U.S. Salinity Laboratory. Riverside. USA

Simunek J, Sejna M, van Genuchten M (1999) The HYDRUS2D software package for simulating the two dimensional movement of water, heat and múltiple solutes in variably saturated media. U.S. Salinity laboratory, Riverside, California

Tarboton K, Wallender P (2000) Finite element grid configurations for drains. J Irrig Drain Eng 126(4):243249. doi:10.1061/(ASCE)0733-9437(2000)126:4(243)

Townley LR (1990) AQUAFEM-N: a multi-layered finite element aquifer flow model, users manul and description. CSIRO division of water resources, Pert

van Genucthen M (1980) A closed form equation for predicting the hydraulic conductivity of unsaturated soils. Soil Sci Soc Am J 44:892-898

Vimoke B, Taylor G (1962) Simulating water flow in soil with an electric resistance network. ARS. USDA 41-65

Yeh G (1999) Computational subsurface hydrology-fluid flows. Kluwer Academic, USA

Zaradny H, Feddes R (1979) Calculation of non steady flow towards a drain in saturated unsaturated soil by finite elements. Agric Water Manag. Elsevier S. P. 2:37-53 